\title{
Evaluation of Phosphorus Indices after Twenty Years of Science and Development
}

\author{
Nathan O. Nelson* and Amy L. Shober
}

The P Index was proposed as a nutrient management tool in 1992 and has been implemented as such for the past decade. However, lack of water quality improvement in agricultural watersheds and discrepancies in $\mathrm{P}$ loss ratings between $\mathrm{P}$ indices have raised questions about continued use of the P Index. In response to these concerns, a symposium was held as part of the 2011 ASA, CSSA, SSSA annual meetings. This symposium produced a special collection of seven papers describing the role of $\mathrm{P}$ indices in $\mathrm{P}$ management, evaluation of $\mathrm{P}$ indices, new models for assessing $\mathrm{P}$ loss, methods to improve $\mathrm{P}$ indices, and changes in producer behavior resulting from $P$ Index use. The objectives of this introductory paper are to provide background on the P Index concept, overviews of the special collection papers, and recommendations for future P Index evaluation and development research. The papers in this special collection conclude that $\mathrm{P}$ indices can provide accurate assessments of $\mathrm{P}$ loss but must be evaluated appropriately. Evaluation will require compiling large regional P loss datasets at field and small watershed scales. Simulation models may be used to generate P loss estimates; however, models must be calibrated and validated to ensure their accuracy. Further development of $\mathrm{P}$ indices will require coordinated regional efforts to identify common $\mathrm{P}$ Index frameworks and standardized interpretations. Stringent P Index evaluations will expand the utility of $\mathrm{P}$ indices for critical source area identification and strategic best management practice implementation by regulatory, education, and scientific communities alike.

Copyright $\odot$ American Society of Agronomy, Crop Science Society of America, and Soil Science Society of America. All rights reserved. No part of this periodical may be reproduced or transmitted in any form or by any means, electronic or mechanical, including photocopying, recording, or any information storage and retrieval system, without permission in writing from the publisher.

J. Environ. Qual. 41

doi:10.2134/jeq2012.0342

Received 5 Sept. 2012.

*Corresponding author (nonelson@ksu.edu).

○ ASA, CSSA, SSSA

5585 Guilford Rd., Madison, WI 53711 USA
A LTHOUgh P IS an essential nutrient to agricultural production, it can contribute to water quality degradation if it is transported from fields to surface water. When added to surface water, $\mathrm{P}$ contributes to eutrophication and associated algal blooms, decreased dissolved oxygen, foul odor, and in general, poor water quality (Correll, 1998; Smith, 2003). Excess $P$ is also an important contributor to the apparent increase in harmful algal blooms in the United States (Hudnell, 2010; Paerl, 2008). These factors have led to a general consensus that long-term solutions to eutrophication and harmful algal bloom problems must include reduction of $P$ inputs from both point and nonpoint sources (Correll, 1998; Dodds and Welch, 2000; Foy, 2005; Hudnell, 2010; Paerl, 2008; Smith, 2003).

The P Index concept was developed to help reduce P loss from agricultural lands (Lemunyon and Gilbert, 1993) and has since become ubiquitous in the field of nutrient management. The initial goals of the P Index were (i) to assess the risk of P transport from a field to water body, (ii) to identify critical parameters that influence P loss, and (iii) to help identify management practices that would decrease P loss from a site (Lemunyon and Gilbert, 1993). The goal of $P$ Index use today is to help producers manage $\mathrm{P}$, particularly manure-based $\mathrm{P}$, while minimizing $\mathrm{P}$ losses and the associated environmental impacts. Included within this goal is the identification of critical source areas and strategic placement of best management practices.

In the 20 years since its inception, considerable research (conducted by multiple teams of scientists) has been devoted to refining and improving the structure of and relationships used within the P Index, as was documented by Sharpley et al. (2011). This research advanced the science and understanding of factors contributing to P loss and concomitantly developed many variations of the P Index concept. Simultaneous to the advances in science, federal and state agencies adopted the $\mathrm{P}$ Index as a tool for policy and regulatory oversight, which introduced political influence into the use and interpretations of P Index ratings (Osmond et al., 2006). For example, the P Index was inserted as an integral component of the USDANRCS Nutrient Management Conservation Practice Standard (Code 590) (USDA-NRCS, 2011a), was part of the USEPA Concentrated Animal Feeding Operation rule (USEPA, 2002),

N.O. Nelson, Dep. of Agronomy, Kansas State Univ., Manhattan, KS 66506; A.L. Shober, Dep. of Plant and Soil Sciences, Univ. of Delaware, Newark, DE. Contribution no. 13-054-J from the Kansas Agricultural Experiment Station, Manhattan, KS. Assigned to Technical Editor Rory Maguire.

Abbreviations: APLE, Annual Phosphorus Loss Estimator; CNMP, certified nutrient management planner; DP, dissolved phosphorus; PP, particulate phosphorus; SERA-17, Southern Extension-Research Activity Group 17; TP, total phosphorus. 
and has been used by multiple states in the permitting of animal feeding operations and regulation of manure applications to agricultural land (DeLaune et al., 2006; Johnson et al., 2005).

Although the P Index is a widely used tool, some questions have been raised about the continued use of the P Index for nutrient management planning. For example, relatively few studies have been conducted to evaluate the accuracy of P Index ratings (Sharpley et al., 2012). Some weighting factors in $\mathrm{P}$ indices appear to have been arbitrarily selected and are poorly justified (Drewry et al., 2011; Lemunyon and Gilbert, 1993). The state-to-state variability in $\mathrm{P}$ indices has raised questions about disagreement in index ratings across state boundaries (Benning and Wortmann, 2005; Osmond et al., 2006). Concerns have been stated over the long-term application of the P Index because the P Index can allow for P application beyond crop requirement, resulting in continual soil test $\mathrm{P}$ buildup in some instances (Kovzelove et al., 2010). Furthermore, there are concerns that use of the P Index is not resulting in improved water quality (Sharpley et al., 2012). These concerns have influenced the use of the P Index for nutrient management planning. Citing concerns in line with those mentioned above, the USEPA recommended the $\mathrm{P}$ saturation soil test in place of the P Index for management of $P$ within the Chesapeake Bay watershed (USEPA, 2010).

Additional information is needed regarding the use, impacts, and evaluation of $\mathrm{P}$ indices to respond to the concerns about the use of $\mathrm{P}$ indices in conservation practice guidance and regulatory oversight. Therefore, the Nutrient Loss Assessment and Prevention community in the Environmental Quality Section of the American Society of Agronomy sponsored a symposium titled "Evaluation and Validation of Phosphorus Indices" as part of the 2011 ASA, CSSA, SSSA Meetings in San Antonio, TX, on 18 Oct. 2011. The P Index evaluation symposium included position and review papers, as well as original research papers related to the use and assessment of $\mathrm{P}$ indices as tools to improve $\mathrm{P}$ management and reduce $\mathrm{P}$ loss. The papers discussed the role of $\mathrm{P}$ indices in $\mathrm{P}$ management, alternative methods for assessing $\mathrm{P}$ loss, evaluation of $\mathrm{P}$ indices relative to measured data, comparisons of P Index results to model results, and changes in behavior resulting from $P$ Index use.

The objectives of the symposium were to review the use and evaluation of $\mathrm{P}$ indices, to present the current methodologies available for evaluation and improvement of $\mathrm{P}$ indices, and to evaluate the potential for $\mathrm{P}$ indices to encourage improved $\mathrm{P}$ management in crop production systems. The objectives of this introductory paper are to review the P Index concept and P Index evaluations conducted to date, to provide an overview of the papers presented in the P Index evaluation symposium, and to identify critical knowledge gaps and research needs related to the use and evaluation of $\mathrm{P}$ indices for the assessment of $\mathrm{P}$ loss from agricultural systems.

\section{Evolution of the Phosphorus Index Concept}

Readers unfamiliar with the P Index are referred to existing literature reviews that have expertly summarized the development of the P Index concept, computational methodology, and associated scientific research (Buczko and Kuchenbuch, 2007; Drewry et al., 2011; Gburek et al., 2000; Heathwaite et al., 2005; Heckrath et al., 2008; Sharpley et al., 2003, 2011; Weld and Sharpley, 2007). Here, we briefly review the original P Index and highlight major advances that have been incorporated into current $\mathrm{P}$ indices.

The original P Index (PI $)$ was computed as the sum of P loss factors $(L)$ multiplied by respective weighting factors $(\beta)$ (Eq. [1]) (Lemunyon and Gilbert, 1993):

$\mathrm{PI}_{\mathrm{o}}=\sum_{i=1}^{n} \beta_{i} L_{i}$

Phosphorus loss factors in the initial P Index included soil erosion, irrigation erosion, runoff, soil test $\mathrm{P}, \mathrm{P}$ fertilizer application rate, $\mathrm{P}$ fertilizer application method, organic $\mathrm{P}$ source application rate, and organic $\mathrm{P}$ source application method. Loss factors were derived from categorical values ranging from 0 (none) to 8 (very high), and weighting factors ranged from 0.5 to 1.5 . The original index is referred to as an additive index because the influence of each P loss factor $(L)$ is summed to produce the final index rating. The original index was computationally simple and used input values that were relatively easy to obtain. However, there was a lack of research to support the selection of arbitrary weighting factors and categorical variables. Furthermore, some loss pathways were misrepresented (e.g., interactions between transport and source factors) or absent (e.g., subsurface P loss) from the computation in the original additive P Index.

Since the inception of the P Index, researchers have made major changes to the structure and content of the index. For example, the computational structure of many $\mathrm{P}$ indices was changed from additive to a multiplicative or component index. Other changes to the P Index included the addition of factors to account for previously omitted P loss processes (e.g., subsurface losses), conversion of categorical variables to continuous variables, and revision of the $\mathrm{P}$ loss weighting factors. The multiplicative index $\left(\mathrm{PI}_{\mathrm{m}}\right)$, suggested by Gburek et al. (2000) and refined by others (Sharpley et al., 2003) separated the P source and transport factors. Therefore, a multiplicative index is the product of $\mathrm{P}$ source factors $(S)$ and $\mathrm{P}$ transport factors $(T)$ (Eq. [2]), reflecting the notion that a large $P$ source would have low risk if there was not any transport mechanism and, vice versa, the risk of a small P source may be magnified if substantial transport processes exist:

$$
\mathrm{PI}_{\mathrm{m}}=\left(\sum_{i=1}^{n} \beta_{i} S_{i}\right)\left(\sum_{j=1}^{m} \chi_{j} T_{j}\right)
$$

where there are $n$ source factors and $m$ transport factors, $\beta_{i}$ is the weighting factor for the $i$ th source factor $(S)$, and $\chi_{j}$ is the weighting factor for the $j$ th transport factor $(T)$.

The component index $(\mathrm{PI})$ is a refinement of the multiplicative index, where each component represents a specific combination of $\mathrm{P}$ sources and associated transport processes (Eq. [3]), reflecting the notion that $\mathrm{P}$ transport pathways may have variable interactions with the $P$ sources (Bolster et al., 2012):

$$
\mathrm{PI}_{\mathrm{c}}=\sum_{i=1}^{n} \sum_{j=1}^{m} \beta_{i j} S_{i} T_{j}
$$

where there are $n$ source factors and $m$ transport factors with $\beta_{i j}$ as the weighting factor for the interaction of the $i$ th source factor $(S)$ and $j$ th transport factor $(T)$. 
Although the original P Index included only eight Ploss factors, as many as 34 input variables have been identified (Osmond et al., 2006). Most of the indices contain the original eight plus or minus a few. Frequently added factors include a $\mathrm{P}$ leaching factor and a distance to stream factor; the irrigation erosion factor is sometimes removed based on regional importance (Sharpley et al., 2003). The categorical nature of $P$ loss factors in the original $\mathrm{P}$ Index resulted in arbitrary breakpoints in the index and limited the maximum values for $\mathrm{P}$ loss factors; therefore, many $\mathrm{P}$ indices have converted categorical variables to continuous variables when possible. The most common continuous variables in the $\mathrm{P}$ Index are erosion, soil test $\mathrm{P}$, and $\mathrm{P}$ application rates.

Authors of the original P Index acknowledged that weighting factors were arbitrarily selected (Lemunyon and Gilbert, 1993). Furthermore, $\mathrm{P}$ loss factor weights have a large impact on index results. It stands to follow that considerable research has been devoted to refining the weighting factors in Eq. [1-3]. However, a thorough review of the research conducted to refine P Index weighting factors is beyond the scope of this paper; the reader is referred to Sharpley et al. (2011) for a listing of over 180 published research studies related to P Index development.

\section{Phosphorus Index Evaluation}

Six general methods are used to evaluate $\mathrm{P}$ indices in the literature (Table 1). Of the $48 \mathrm{P}$ indices created in the United States, 22 were evaluated to some degree in peer-reviewed literature (Table 2). These P Index evaluations had diverse objectives and methodologies. Furthermore, some indices have been much more thoroughly evaluated than others. Seventeen $P$ indices were evaluated through comparison with $\mathrm{P}$ loss ratings from other $\mathrm{P}$ indices (i.e., multiple indices were used to determine the risk of $\mathrm{P}$ loss from the same set of fields and results were compared) (Benning and Wortmann, 2005; Osmond et al., 2006). Comparison of index evaluations of the same fields identified wide discrepancies between $P$ Index ratings and determined that changes in $\mathrm{P}$ loss factors had inconsistent effects on P Index ratings. For example, $P$ loss ratings from some $\mathrm{P}$ indices are strongly influenced by erosion, whereas others are influenced more by soil test P. A few researchers conducted formal sensitivity analysis to determine which $\mathrm{P}$ loss factors had the greatest impact on P Index ratings (Brandt and Elliott, 2005; Jesiek and Wolfe, 2005). Although comparisons of P loss ratings between indices are good for identifying differences among $\mathrm{P}$ indices, they do not indicate if a P Index is an accurate risk assessment tool. Furthermore, differences among indices may be due to the differences in predominant processes influencing $\mathrm{P}$ loss within the physiographic region for which the specific $\mathrm{P}$ Index was designed (Osmond et al., 2006).

Evaluation of the accuracy of a P Index for identifying fields that are at greatest risk for $\mathrm{P}$ loss requires comparison of $\mathrm{P}$ Index ratings to a separate independent, valid assessment of $\mathrm{P}$ loss. Phosphorus loss assessments used in the literature include measured data from runoff simulation studies, measured data from field-scale P loss studies, and estimates from watershed- or field-scale models. Phosphorus Index evaluation using field-scale natural runoff plots was the most frequently used method (Table 2 ), with evaluations producing varied results depending on the $P$ Index being evaluated and the techniques of evaluation. In general, $P$ Index ratings and measured data were poorly correlated $(r=0.30-0.55)$ when the $\mathrm{P}$ indices were computed using runoff and soil erosion estimates independent of the measured data (Good et al., 2012; Harmel et al., 2005). However, correlations were greatly improved if $\mathrm{P}$ indices were computed using the measured runoff and erosion estimates from actual field studies. Correlation coefficients $(r)$ for measured P loss vs. P indices determined by the studies listed in Table 2 ranged from $<0.01$ to 0.98 ; results indicated that although some $\mathrm{P}$ indices provide adequate assessments of $P$ loss risk, others will need to be revised and improved.

\section{Summaries of Papers Included in the Special Section}

Authors from 7 of the 15 ASA symposium presentations developed papers for this special collection. The papers are grouped into the following five general topics related to $P$ indices.

\section{Phosphorus Indices as Part of the NRCS Nutrient Management Conservation Practice Standard}

In 2009, a group of scientists from the Southern ExtensionResearch Activity Group 17 (SERA-17) cooperated with the USDA-NRCS to review proposed changes to the Nutrient Management Conservation Practice Standard (code 590). Sharpley et al. (2012) summarize the deliberations and recommendations produced by this group. The authors review

Table 1. Summary of published methods used to evaluate $P$ indices (see Table 2 for the listing of corresponding references).

\begin{tabular}{|c|c|c|}
\hline ID & Method & Description \\
\hline $\bar{A}$ & $\begin{array}{l}\text { Comparison with other } P \\
\text { indices }\end{array}$ & $\begin{array}{l}\text { Comparison of how multiple P indices rank a given field (or set of fields) and how the P Index ratings change in } \\
\text { response to changes in management }\end{array}$ \\
\hline B & Sensitivity analysis & $\begin{array}{l}\text { Systematically altering individual inputs to a } \mathrm{P} \text { Index and comparing the relative change in } \mathrm{P} \text { Index ratings to the } \\
\text { relative change in the inputs }\end{array}$ \\
\hline C & $\begin{array}{l}\text { Simulated rainfall runoff from } \\
\text { small plots }\end{array}$ & $\begin{array}{l}\text { Comparison of } \mathrm{P} \text { Index ratings to measured } \mathrm{P} \text { loss data from small, simulated runoff studies under a range of } \\
\text { management or soil conditions }\end{array}$ \\
\hline D & Simulation model data & $\begin{array}{l}\text { Comparison of } \mathrm{P} \text { Index ratings to } \mathrm{P} \text { losses estimated by independently validated computer models for a range of } \\
\text { management and soil conditions }\end{array}$ \\
\hline $\mathrm{E}$ & Edge-of-field measured data & $\begin{array}{l}\text { Comparison of } \mathrm{P} \text { Index ratings to measured annual } \mathrm{P} \text { loss from fields subjected to natural rainfall with a range of } \\
\text { management or soil conditions }\end{array}$ \\
\hline $\mathrm{F}$ & $\begin{array}{l}\text { Watershed-scale measured } \\
\text { data }\end{array}$ & $\begin{array}{l}\text { Comparison of area-weighed } \mathrm{P} \text { Index values to stream water } \mathrm{P} \text { concentrations or } \mathrm{P} \text { losses measured at a watershed } \\
\text { outlet }\end{array}$ \\
\hline G & Other method of evaluation & $\begin{array}{l}\text { Methods of evaluation not covered above, e.g., comparison of } \mathrm{P} \text { Index values with } \mathrm{P} \text { concentrations in stream } \\
\text { sediment, evaluation of the potential effects of } \mathrm{P} \text { indices on } \mathrm{P} \text { application rates, evaluation of producer behavior } \\
\text { in response to } \mathrm{P} \text { Index ratings, etc. }\end{array}$ \\
\hline
\end{tabular}


methodologies for assessing risk of $\mathrm{P}$ loss within the context of recent suggestions that soil tests replace the P Index in the Chesapeake Bay region (Kovzelove et al., 2010). The advantages and disadvantages of using agronomic soil tests, environmental thresholds, soil $\mathrm{P}$ saturation, and $\mathrm{P}$ indices are discussed. Sharpley et al. (2012) make the case that a well-designed P Index can provide much better assessment of $\mathrm{P}$ loss risk from agricultural areas than an agronomic or environmental soil test $\mathrm{P}$ threshold because the P Index approach accounts for source and transport factors. However, the authors note that proper evaluation of $\mathrm{P}$ indices using measured or simulated (using vetted models) P loss data is critical. One drawback of $\mathrm{P}$ indices discussed by the authors is that $\mathrm{P}$ indices are not designed to address the issues of regional $\mathrm{P}$ imbalances that are common to areas of intensive animal production. The authors suggest some long-term goals related to improvement of the P Index, including the development of "next-generation" $\mathrm{P}$ indices that extend beyond state boundaries and the use of GIS to distinguish variations in site properties at smaller scales. In conclusion, Sharpley et al. (2012) suggest that coordinated efforts to improve state or regional $\mathrm{P}$ indices can lessen the discrepancies between $\mathrm{P}$ indices and improve our ability to assess P loss risk.

\section{Assessment of Phosphorus Losses from Tile Drains}

Assessing the risk of subsurface $\mathrm{P}$ losses has generally received less attention than assessing $\mathrm{P}$ losses through surface runoff and erosion. Therefore, many of the $\mathrm{P}$ indices have underdeveloped science supporting subsurface components or have ignored subsurface P losses altogether. Reid et al. (2012) provide a summary of current approaches for assessing the risk of P loss through tile drainage systems and contrast these methods with a review of literature on the physical processes influencing subsurface $\mathrm{P}$ transport and loss from tile-drained soils. The authors propose a new method for including consideration of subsurface P loss from tile-drained soils within a standard component P Index framework and conclude that further data collection and index evaluation are needed to validate the proposed model.

\section{Evaluation of Phosphorus Indices Using Measured Data}

Good et al. (2012) evaluated the ability of the Wisconsin $\mathrm{P}$ Index (a component index) to predict $\mathrm{P}$ loss using measured total P (TP), dissolved P (DP) and particulate P (PP) (where $\mathrm{PP}=\mathrm{TP}-\mathrm{DP})$ loss from field-scale monitoring data collected from cropped fields between 2003 and 2008. The authors report weak relationships between Wisconsin P Index values (estimate of $\mathrm{P}$ loss using long-term climatic data) and measured DP, PP, and TP $\left(r^{2}=0.36,0.28\right.$, and 0.24 , respectively). An evaluation of

Table 2. Summary of the $P$ indices that have been evaluated and the respective evaluation methodologies employed (numbers indicate number of studies using the evaluation method).

\begin{tabular}{|c|c|c|c|c|c|c|c|c|}
\hline \multirow{2}{*}{ Index } & \multicolumn{7}{|c|}{ Method of evaluationt } & \multirow{2}{*}{ References } \\
\hline & A & B & $\mathrm{C}$ & D & $\mathrm{E}$ & $\mathrm{F}$ & G & \\
\hline Lemunyon and Gilbert & & & 1 & & 1 & 1 & & Birr and Mulla, 2001; Eghball and Gilley, 2001; Sharpley, 1995 \\
\hline Alabama & 1 & & & & 1 & & & Osmond et al., 2006, 2012 \\
\hline Arkansas & 1 & & & & 3 & & & DeLaune et al., 2004; Harmel et al., 2005; Osmond et al., 2006, 2012 \\
\hline Florida & 1 & & & & 1 & & & Osmond et al., 2006, 2012 \\
\hline Georgia & 1 & & & & 2 & & & Butler et al., 2010; Osmond et al., 2006, 2012 \\
\hline lowa & 1 & & & & 1 & & & Benning and Wortmann, 2005; Harmel et al., 2005 \\
\hline Kansas & 1 & & 1 & & 1 & & & Benning and Wortmann, 2005; Sonmez et al., 2009 \\
\hline Kentucky & 1 & & & & & & & Osmond et al., 2006 \\
\hline Louisiana & 1 & & & & 1 & & & Osmond et al., 2006, 2012 \\
\hline Mississippi & 1 & & & & 1 & & & Osmond et al., 2006, 2012 \\
\hline Missouri & 1 & & & & & & & Benning and Wortmann, 2005 \\
\hline Nebraska & 1 & & & & & & & Benning and Wortmann, 2005 \\
\hline New Mexico & 1 & & & & & & & Osmond et al., 2006 \\
\hline New York & & & & & & & 1 & Ketterings and Czymmek, 2012 \\
\hline North Carolina & 1 & & & & 1 & & 2 & Israel et al., 2007; Johnson et al., 2005; Osmond et al., 2006, 2012 \\
\hline Oklahoma & 1 & & & & 1 & & & Osmond et al., 2006, 2012 \\
\hline Pennsylvania & & 1 & 1 & 3 & 1 & 1 & & $\begin{array}{l}\text { Andersen and Kronvang, 2006; Bolster et al., 2012; Brandt and Elliott, } \\
\text { 2005; Buda et al., 2009;Sharpley et al., 2001; Veith et al., } 2005\end{array}$ \\
\hline South Carolina & 1 & & & & 1 & & & Osmond et al., 2006, 2012 \\
\hline Tennessee & 1 & & & & 1 & & & Osmond et al., 2006, 2012 \\
\hline Texas & 1 & & & & 2 & & & Harmel et al., 2002; Harmel et al., 2005; Osmond et al., 2006, 2012 \\
\hline Virginia & & 1 & & & & & & Jesiek and Wolfe, 2005 \\
\hline Washington & & & & & & & 1 & Schendel et al., 2004 \\
\hline Wisconsin & & & & & 1 & & & Good et al., 2012 \\
\hline Danish & & & & & & 1 & & Andersen and Kronvang, 2006 \\
\hline Quebec & & 1 & & & 1 & & & Beaulieu et al., 2006; Goulet et al., 2006 \\
\hline Swedish & & & & & 1 & & & Djodjic and Bergstrom, 2005 \\
\hline
\end{tabular}

† A: comparison with other P indices; B: sensitivity analysis; C: simulated rainfall runoff from small plots; D: simulation model data; E: edge-of-field measured data; F: watershed-scale measured data; G: other method of evaluation. 
Wisconsin P Index values during years with higher than average rainfall showed that Wisconsin $\mathrm{P}$ Index values tended to be lower than measured values; the opposite trend was observed during dry years. In addition, tilled fields tended to lose more PP than predicted by the Wisconsin P Index or the RUSLE2 soil loss equation. In contrast, Good et al. (2012) report stronger relationships when actual rainfall, runoff, and erosion data were used to calculate P Index values $\left(r^{2}=0.76\right.$ [ $\ln$ transformed], 0.94, and 0.84 for DP, PP, and TP, respectively). The authors reveal that the Wisconsin P Index calculations were highly influenced by management changes at the field-scale that affect runoff or erosion potential. They conclude that the Wisconsin P Index provided an accurate assessment of field-level $\mathrm{P}$ loss when erosion and runoff predictions were correct.

Osmond et al. (2012) evaluated $12 \mathrm{P}$ indices (3 additive, 6 multiplicative, 2 component, and 1 other) from states in the southern United States using measured P loss data collected during field studies in Alabama, Arkansas, Georgia, Mississippi, and Oklahoma. Of the 12P indices evaluated, 5 indices (Arkansas, Florida, Georgia, North Carolina, and South Carolina) showed strong correlation between P Index values and measured TP and DP loads; all evaluated indices were deemed directionally correct, with the exception of Mississippi for TP and Alabama and Mississippi for DP. The P indices that best predicted TP and DP were multiplicative or component; the additive and some multiplicative indices did not perform well. Osmond et al. (2012) also compared P Index ratings, determining that all indices could accurately identify fields with low risk of $\mathrm{P}$ loss but that many were not able to accurately predict medium or high risk of $\mathrm{P}$ loss. Current $\mathrm{P}$ indices are developed at state boundaries because the regulations governing $P$ management are developed at the state level. However, Osmond et al. (2012) suggest the need to develop P indices based on local physiographic features rather than state boundaries.

\section{Evaluation of Phosphorus Indices Using Simulated Data}

One option for evaluation of $\mathrm{P}$ indices is to compare P Index results to model estimates of P loss. Use of simulation model data as the benchmark for P Index evaluation requires generation of accurate $\mathrm{P}$ loss estimates for unknown situations. Therefore, the $\mathrm{P}$ cycling subroutines in models used to generate $\mathrm{P}$ loss estimates must undergo rigorous testing to ensure that models can simulate management impacts on P cycling and loss across soils with a wide range of $P$ sorption characteristics. Vadas et al. (2012) tested the ability of the Annual Phosphorus Loss Estimator (APLE) model to predict changes in soil P status of soils over time. This study found that APLE was able to accurately predict changes in Mehlich $3 \mathrm{P}$ under management systems where $\mathrm{P}$ is being either added or depleted from the soil. The authors also found that the APLE model accurately predicted the accumulation of TP in surface and subsurface of no-till soils receiving $P$ inputs, indicating that the model can account for effects of $\mathrm{P}$ leaching. These results demonstrate that APLE can reliably simulate changes in soil $P$ resulting from long-term management practices, which is a critical component of predicting management practice effects on P loss.

Bolster et al. (2012) compared multiplicative and component versions of the Pennsylvania P Index, and building on the work of Vadas et al. (2012), used the APLE model to improve the weighting factors used in the $\mathrm{P}$ indices. When compared against measured $\mathrm{P}$ loss data from 26 independent studies, index values from the component version of the Pennsylvania P Index were more highly correlated with measured $\mathrm{P}$ loss than were index values from the multiplicative index. Multiple regression analysis between P Index factors and APLE simulated P loss estimates was used to select for an optimal set of weighting factors. The new weighting factors substantially improved the correlation between $P$ Index results and measured data. The methods and results presented by Bolster et al. (2012) demonstrate how modeled data can be used to improve $\mathrm{P}$ indices.

\section{Phosphorus Index Effects on Nutrient Management Planning Efforts}

The ultimate goal of the P Index is to encourage improved $\mathrm{P}$ management in agricultural fields. Therefore, evaluating the impact of P Index-based nutrient management planning on producer behavior is equally as important as evaluating the $\mathrm{P}$ Index itself. Ketterings and Czymmek (2012) evaluated changes in P management by New York dairy producers through surveys filled out by certified nutrient management planners (CNMPs). The results were compared to data on fertilizer use, soil test $\mathrm{P}$, and whole farm nutrient budgets. The CNMPs indicated that P Index results caused producers to change manure application rates and increase off-farm manure export. Fertilizer sales data showed that since the release of the New York P Index in 2001, P fertilizer use decreased by $35 \%$; nutrient management plans indicated a $44 \%$ decrease in surplus $\mathrm{P}$ on dairy farms. These decreases in fertilizer use and surplus $\mathrm{P}$ on dairies, combined with changes in manure management, corresponded to a general perception by CNMPs that the percentage of soils with "very high" soil test $\mathrm{P}$ classification has decreased. Regional soil test data support the assertion that there is a decrease in fields with very high soil test $P$. Survey data showed the positive impact of that P Index-based nutrient management planning can have on manure and $P$ management practices.

\section{Gaps in Knowledge and Recommendations for Research}

Phosphorus Index development stimulated considerable research attention and generated considerable scientific information related to P loss estimation (Sharpley et al., 2011). The papers in this special collection highlight some of the positive impacts resulting from this research and the implementation of the P Index. However, they also reveal the need for future work in the development, evaluation, improvement, and implementation of $\mathrm{P}$ indices. The gaps in knowledge and needs for future research fall into three general areas: (i) P Index evaluation, (ii) advancement of $P$ indices, and (iii) interpretation and implementation of $\mathrm{P}$ Index results.

\section{Phosphorus Index Evaluation}

Although many P indices have been evaluated, the majority of $P$ indices in use in the United States have not been fully assessed (Table 2). Evaluations to this point have produced mixed results, identifying some indices that can accurately assess the risk of $\mathrm{P}$ loss and other indices with poor P risk assessment capability 
(Harmel et al., 2005; Osmond et al., 2012). There is a critical need to evaluate all $\mathrm{P}$ indices to determine if they are correctly identifying the impact of soil, climate, and management practices on the magnitude and direction of P loss (Sharpley et al., 2012). Standard evaluation protocols need to be developed to ensure that all $\mathrm{P}$ indices are adequately evaluated. In addition, general evaluation standards need to be outlined to appropriately define acceptable and unacceptable evaluation results. Many P indices were already evaluated through comparisons with measured fieldscale P loss data (DeLaune et al., 2004; Good et al., 2012; Harmel et al., 2005; Osmond et al., 2012); however, the techniques used to complete these evaluations varied widely. Some studies only used measured runoff, precipitation, and erosion as inputs to $\mathrm{P}$ Index calculations when comparing to measured data (Osmond et al., 2012), whereas other studies computed the P Index independent of the measured data (Good et al., 2012; Harmel et al., 2005). Several other studies did not indicate if the P Index was computed independent of the measured data (Butler et al., 2010; DeLaune et al., 2004; Djodjic and Bergstrom, 2005; Sonmez et al., 2009).

Phosphorus indices generally use RUSLE2 to estimate erosion losses, and when needed, runoff and precipitation are estimated with long-term average annual values. Therefore, when used for nutrient management planning, the P Index values represent the risk of $\mathrm{P}$ loss with erosion and runoff representative of long-term average conditions. However, measured P loss data available for use in P Index evaluation were often collected over short periods of time (i.e., 1 to $3 \mathrm{yr}$ ), during which time highly variable climate conditions were observed. Therefore, the transport factors in action for the observed data are not representative of the inputs to the transport components in the P Index (e.g., longterm average annual runoff and erosion). This can create invalid comparisons between P Index values and measured data because the P Index was not designed to predict annual losses. One way to compensate for the discrepancy between the site-specific annual nature of the measured data and the long-term average nature of P Index ratings is to modify the P Index computation with site-specific measured data (e.g., observed annual runoff, erosion, and/or precipitation) as inputs for P Index transport factors (Good et al., 2012; Harmel et al., 2005). It is important to note that this type of comparison will not be an independent evaluation of $\mathrm{P}$ indices because $\mathrm{P}$ Index results are dependent on the measured data to which the index is being compared. However, this method of evaluation can be useful for evaluating the $\mathrm{P}$ source components of $\mathrm{P}$ indices.

Large $\mathrm{P}$ loss datasets are needed for evaluation of $\mathrm{P}$ indices with measured data to ensure that results are not biased by climatic conditions observed during data collection. Currently, $\mathrm{P}$ loss datasets meeting these criteria are only available for limited geographic regions of the United States. Collection and organization of adequate datasets is an important component of the $P$ Index evaluation process.

Because a sufficient quantity of measured P loss data is not available for P Index evaluation in all geographic regions and the use of measured data is not an independent evaluation of $\mathrm{P}$ indices, simulation models may serve as an alternative method for generating the $\mathrm{P}$ loss datasets needed for evaluation of $\mathrm{P}$ indices (Sharpley et al., 2012). Computer model datasets can allow for independent evaluation of $\mathrm{P}$ indices because computer models can develop estimates of long-term average $\mathrm{P}$ losses. However, computer models must be adequately calibrated and validated before generating P loss estimates for $P$ Index evaluation. Many computer models are available for predicting management impacts on water quality, but not all of them have been rigorously validated with respect to P loss. In addition, not all the advances in modeling $\mathrm{P}$ loss have been incorporated into computer models. Therefore, substantial efforts must be made to update, calibrate, and validate models with respect to simulation of soil $P$ processes and estimation of P losses. Data simulation may be more feasible than widespread measurement of field scale P loss over large geographic areas and long time frames.

Most $\mathrm{P}$ indices contain factors that modify the index rating based on specific site conditions (e.g., distance to a stream, soil drainage) or the adoption of best management practices at the site (e.g., the presence and width of a buffer). Many of these site conditions were not present or reported as part of the field-level P loss datasets available for P Index calibration. Furthermore, models have limited ability to simulate the effects of these factors on P loss. Because of the lack of information concerning how site-specific conditions influence P delivery to waterbodies, P Index evaluation studies often ignore or generalize these factors. Therefore, additional work will need to be done to adequately evaluate the best management practice components of $\mathrm{P}$ indices.

\section{Phosphorus Index Development}

Phosphorus Index evaluations have identified, and will undoubtedly continue to identify, weaknesses in $\mathrm{P}$ indices. Information obtained from the evaluation of $\mathrm{P}$ indices should lead to improvements and advancements in the P Index concept. Potential improvements expected to result from $\mathrm{P}$ Index evaluations include improved weighting factors, development and adoption of regional $\mathrm{P}$ indices, and an improved P Index framework (i.e., additive, multiplicative, or component). However, researchers have yet to identify the most appropriate way to achieve these advancements in the P Index. Additional research should identify the most appropriate ways to improve P Index weighting factors and update the P Index framework. It is unknown if evaluation datasets, measured or modeled, can be used to determine the most appropriate weighting factors. Perhaps there are specific weighting factors that should be determined through laboratory or field experiments. In addition, researchers need to determine if there is a superior framework that should be used universally when updating $\mathrm{P}$ indices. Some of these questions can be answered through active discourse among members of the scientific community, whereas others will need to be answered through directed research studies.

\section{Phosphorus Index Interpretation and Implementation}

The eventual index interpretation and implementation should be considered throughout the evaluation and development process. Although $\mathrm{P}$ indices produce continuous (or semicontinuous) numerical output, the numerical value is interpreted as a qualitative risk. The traditional P Index risk categories are low, medium, high, and very high. The associated interpretations generally allow $\mathrm{N}$-based manure management for low and medium $\mathrm{P}$ loss risk, restrict $\mathrm{P}$ additions to crop removal 
when $\mathrm{P}$ loss risk is high, and prohibit $\mathrm{P}$ applications when $\mathrm{P}$ loss risk is very high. However, considerable variability in the way states interpret the index ratings remains. Many questions relating to the selection of breakpoints associated with P Index interpretations remain unanswered. For example, can or should breakpoints be associated with water quality objectives? Should breakpoints be based on an "average" risk of P loss or the risk of $\mathrm{P}$ loss for an extreme event, such as a design event? How can breakpoints and interpretations between diverse indices be standardized (i.e., recommend the same P management for a given scenario)?

As previously mentioned, the $\mathrm{P}$ Index will allow for overapplication of $\mathrm{P}$ when the risk for $\mathrm{P}$ loss is low. This causes continual $\mathrm{P}$ buildup and $\mathrm{P}$ imbalance at the field and farm scale, which is not a long-term sustainable practice. Once fields reach a high risk of $\mathrm{P}$ loss, then $\mathrm{P}$ additions must be in balance with crop $P$ removal, thus bringing balance to the field and eventually to the whole farm. Therefore, the interpretation of P Index ratings will eventually drive producers to a field- and farm-scale P balance. The breakpoints of these interpretations will determine the $P$ loss at which producers will maintain equilibrium.

A recently revised version of the USDA-NRCS National Instruction (Title 190, Section 302) called for standardization of P loss risk categories in all P indices (USDA-NRCS, 2011b). The recommended standardization was based on the mass of $\mathrm{P}$ loss, which would require all $\mathrm{P}$ indices to be calibrated to quantitative $\mathrm{P}$ loss estimates. These methods of standardization must be considered when evaluating $\mathrm{P}$ indices. Furthermore, changing demands on $P$ indices will need to be considered when revising and developing new $\mathrm{P}$ indices.

\section{References}

Andersen, H.E., and B. Kronvang. 2006. Modifying and evaluating a P index for Denmark. Water Air Soil Pollut. 174:341-353. doi:10.1007/ s11270-006-9123-0

Beaulieu, L., J. Gallichand, M. Duchemin, and L.E. Parent. 2006. Sensitivity analysis of a phosphorus index for Québec. Can. Biosystems Eng. 48:1.13-1.24.

Benning, J.L., and C.S. Wortmann. 2005. Phosphorus indexes in four midwestern states: An evaluation of the differences and similarities. J. Soil Water Conserv. 60:221-227.

Birr, A., and D. Mulla. 2001. Evaluation of the phosphorus index in watersheds at the regional scale. J. Environ. Qual. 30:2018-2025. doi:10.2134/ jeq2001.2018

Bolster, C.H., P.A. Vadas, A.N. Sharpley, and J.A. Lory. 2012. Using a phosphorus loss model to evaluate and improve phosphorus indices. J. Environ. Qual. 41:1758-1766 (this issue). doi:10.2134/jeq2011.0457

Brandt, R., and H. Elliott. 2005. Sensitivity analysis of the Pennsylvania phosphorus index for agricultural recycling of municipal biosolids. J. Soil Water Conserv. 60:209-219.

Buczko, U., and R.O. Kuchenbuch. 2007. Phosphorus indices as risk-assessment tools in the USA and Europe: A review. J. Plant Nutr. Soil Sci. Z. Pflanzenernaehr. Bodenkd. 170:445-460. doi:10.1002/jpln.200725134

Buda, A.R., P.J.A. Kleinman, M.S. Srinivasan, R.B. Bryant, and G.W. Feyereisen. 2009. Effects of hydrology and field management on phosphorus transport in surface runoff. J. Environ. Qual. 38:2273-2284. doi:10.2134/jeq2008.0501

Butler, D.M., D.H. Franklin, M.L. Cabrera, L.M. Risse, D.E. Radcliffe, L.T. West, and J.W. Gaskin. 2010. Assessment of the Georgia phosphorus index on farm at the field scale for grassland management. J. Soil Water Conserv. 65:200-210. doi:10.2489/jswc.65.3.200

Correll, D. 1998. The role of phosphorus in the eutrophication of receiving waters: A review. J. Environ. Qual. 27:261-266. doi:10.2134/ jeq1998.00472425002700020004x

DeLaune, P., B. Haggard, T. Daniel, I. Chaubey, and M. Cochran. 2006. The Eucha/Spavinaw phosphorus index: A court mandated index for litter management. J. Soil Water Conserv. 61:96-105.
DeLaune, P., P. Moore, D. Carman, A. Sharpley, B. Haggard, and T. Daniel. 2004. Evaluation of the phosphorus source component in the phosphorus index for pastures. J. Environ. Qual. 33:2192-2200. doi:10.2134/ jeq2004.2192

Djodjic, F., and L. Bergstrom. 2005. Conditional phosphorus index as an educational tool for risk assessment and phosphorus management. Ambio 34:296-300.

Dodds, W., and E. Welch. 2000. Establishing nutrient criteria in streams. J. North Am. Benthol. Soc. 19:186-196. doi:10.2307/1468291

Drewry, J.J., L.T.H. Newham, and R.S.B. Greene. 2011. Index models to evaluate the risk of phosphorus and nitrogen loss at catchment scales. J. Environ. Manage. 92:639-649. doi:10.1016/j.jenvman.2010.10.001

Eghball, B., and J. Gilley. 2001. Phosphorus risk assessment index evaluation using runoff measurements. J. Soil Water Conserv. 56:202-206.

Foy, R.H. 2005. The return of the phosphorus paradigm: Agricultural phosphorus and eutrophication. In: J.T. Sims and A.N. Sharpley, editors, Phosphorus: Agriculture and the environment. ASA, CSSA, SSSA, Madison, WI. p. 911-939.

Gburek, W., A. Sharpley, L. Heathwaite, and G. Folmar. 2000. Phosphorus management at the watershed scale: A modification of the phosphorus index. J. Environ. Qual. 29:130-144. doi:10.2134/ jeq2000.00472425002900010017x

Good, L.W., P. Vadas, J.C. Panuska, C.A. Bonilla, and W.E. Jokela. 2012. Testing the Wisconsin P Index with year-round, field-scale runoff monitoring. J. Environ. Qual. 41:1730-1740 (this issue). doi:10.2134/jeq2012.0001

Goulet, M., J. Gallichand, M. Duchemin, and M. Giroux. 2006. Measured and computed phosphorus losses by runoff and subsurface drainage in eastern Canada. Appl. Eng. Agric. 22:203-213.

Harmel, R., H. Torbert, P. Delaune, B. Haggard, and R. Haney. 2005. Field evaluation of three phosphorus indices on new application sites in Texas. J. Soil Water Conserv. 60:29-42.

Harmel, R., P. Delaune, B. Haggard, H. Torbert, C.W. Richardson, P. Moore, Jr., and $\mathrm{H}$. Torbert. 2002. Initial evaluation of a phosphorus index on pasture and cropland watersheds in Texas. In: Initial evaluation of a phosphorus index on pasture and cropland watersheds in Texas. Chicago, IL. 28-31 July. American Society of Agricultural Engineers, St. Joseph, MI.

Heathwaite, A.L., A. Sharpley, M. Bechmann, and S. Rekolainen. 2005. Assessing the risk and magnitude of agricultural nonpoint source phosphorus pollution. In: J.T. Sims and A.N. Sharpley, editors, Phosphorus: Agriculture and the environment. ASA, CSSA, SSSA, Madison, WI. p. 981-1020.

Heckrath, G., M. Bechmann, P. Ekholm, B. Ulen, F. Djodjic, and H.E. Andersen. 2008. Review of indexing tools for identifying high risk areas of phosphorus loss in Nordic catchments. J. Hydrol. 349:68-87. doi:10.1016/j.jhydrol.2007.10.039

Hudnell, H.K. 2010. The state of US freshwater harmful algal blooms assessments, policy, and legislation. Toxicon 55:1024-1034. doi:10.1016/j. toxicon.2009.07.021

Israel, D.W., D.L. Osmond, and J.C. Roberts. 2007. Potential impacts of implementation of the phosphorus loss assessment tool (PLAT) on the poultry industry in North Carolina: Case studies. J. Soil Water Conserv. 62:48-54.

Jesiek, J.B., and M.L. Wolfe. 2005. Sensitivity analysis of the Virginia phosphorus index management tool. Trans. ASAE 48:1773-1781.

Johnson, A., D. Osmond, and S. Hodges. 2005. Predicted impact and evaluation of North Carolina's phosphorus indexing tool. J. Environ. Qual. 34:18011810. doi: $10.2134 /$ jeq2005.0020

Ketterings, Q.M., and K.J. Czymmek. 2012. Phosphorus index as a phosphorus awareness tool: Documented phosphorus use reduction in New York State. J. Environ. Qual. 41:1767-1773 (this issue). doi:10.2134/ jeq2012.0050

Kovzelove, C., T. Simpson, and R. Korcak. 2010. Quantification and implications of surplus phosphorus and manure in major animal production regions of Maryland, Pennsylvania, and Virginia. Water Stewardship, Annapolis, MD. http://waterstewardshipinc.org/ downloads/P_PAPER_FINAL_2-9-10.pdf (accessed 24 Sept. 2012).

Lemunyon, J., and R. Gilbert. 1993. The concept and need for a phosphorus assessment-tool. J. Prod. Agric. 6:483-486.

Osmond, D.L., M.L. Cabrera, S.E. Feagley, G.E. Hardee, C.C. Mitchell, P.A Moore, R.S. Mylavarapu, J.L. Oldham, J.C. Stevens, W.C. Thom, F. Walker, and H. Zhang. 2006. Comparing ratings of the southern phosphorus indices. J. Soil Water Conserv. 61:325-337.

Osmond, D., A. Sharpley, C. Bolster, M. Cabrera, S. Feagley, B. Lee, C. Mitchell, R. Mylavarapu, L. Oldham, F. Walker, and H. Zhang. 2012. Comparing phosphorus indices from twelve southern U.S. states against monitored phosphorus loads from six prior southern studies. J. Environ. Qual. 41:1741-1749 (this issue). doi:10.2134/jeq2012.0013 
Paerl, H.W. 2008. Nutrient and other environmental controls of harmful cyanobacterial blooms along the freshwater-marine continuum. In: H.K. Hundell, editor, Cyanobacterial harmful algal blooms: State of the science and research needs. Springer Press, New York. p. 218-237.

Reid, D.K., B. Ball, and T.Q. Zhang. 2012. Accounting for the risks of phosphorus losses through tile drains in a phosphorus index. J. Environ. Qual. 41:1720-1729 (this issue). doi:10.2134/jeq2012.0238

Schendel, E., H. Schreier, and L. Lavkulich. 2004. Linkages between phosphorus index estimates and environmental quality indicators. J. Soil Water Conserv. 59:243-251.

Sharpley, A. 1995. Identifying sites vulnerable to phosphorus loss in agricultural runoff. J. Environ. Qual. 24:947-951. doi:10.2134/ jeq1995.00472425002400050024x

Sharpley, A., D. Beegle, C. Bolster, L. Good, B. Joern, Q. Ketterings, J. Lory, R. Mikkelsen, D. Osmond, and P. Vadas. 2011. Revision of the 590 nutrient management standard: SERA-17 supporting documentation. Rep. Southern Cooperative Series Bull. 413. Virginia Tech Univ., Blacksburg, VA.

Sharpley, A., D. Beegle, C. Bolster, L. Good, B. Joern, Q. Ketterings, J. Lory, R. Mikkelsen, D. Osmond, and P. Vadas. 2012. Phosphorus indices: Why we need to take stock of how we are doing. J. Environ. Qual. 41:1710-1719 (this issue). doi: 10.2134/jeq2012.0040

Sharpley, A.N., R.W. McDowell, J.L. Weld, and P.J.A. Kleinman. 2001. Assessing site vulnerability to phosphorus loss in an agricultural watershed. J. Environ. Qual. 30:2026-2036. doi:10.2134/jeq2001.2026

Sharpley, A., J. Weld, D. Beegle, P. Kleinman, W. Gburek, P. Moore, and G. Mullins. 2003. Development of phosphorus indices for nutrient management planning strategies in the united states. J. Soil Water Conserv. $58: 137-152$.

Smith, V. 2003. Eutrophication of freshwater and coastal marine ecosystems: A global problem. Environ. Sci. Pollut. Res. 10:126-139. doi:10.1065/ espr2002.12.142
Sonmez, O., G.M. Pierzynski, L. Frees, B. Davis, D. Leikam, D.W. Sweeney, and K.A. Janssen. 2009. A field-based assessment tool for phosphorus losses in runoff in Kansas. J. Soil Water Conserv. 64:212-222. doi:10.2489/ jswc.64.3.212

USDA-NRCS. 2011a. Conservation practice standard, nutrient management. Rep. Code 590. USDA-NRCS, Washington, DC. http:www.nrcs.usda. gov/Internet/FSE_DOCUMENTS/stelprdb1046177.pdf (accessed 24 Sept. 2012).

USDA-NRCS. 2011b. National instruction title 190, part 302- Nutrient management policy implementation. Rep. NI 190 302. USDANRCS, Washington, DC. http://directives.sc.egov.usda.gov/viewerFS. aspx ?hid $=31187$ (accessed 24 Sept. 2012).

USEPA. 2002. Technical support document for the revisions to the national pollutant discharge elimination system regulations for concentrated animal feeding operations. Rep. EPA-821-R-03-002. USEPA Water Permits Division, Office of Wastewater Management, Washington, DC. Available at http://www.epa.gov/npdes/pubs/cafo_tech_support.pdf (accessed 24 Sept. 2012).

USEPA. 2010. Guidance for federal land management in the Chesapeake bay watershed. Chapter 2: Agriculture. Rep. EPA841-R-10-002. USEPA, Nonpoint Source Pollution, Office of Wetlands, Oceans, and Watersheds, Washington, DC. http://www.epa.gov/nps/chesbay502/pdf/chesbay_ chap02.pdf (accessed 24 Sept. 2012).

Vadas, P.A., B.C. Joern, and P.A. Moore, Jr. 2012. Simulating soil phosphorus dynamics for a phosphorus loss quantification tool. J. Environ. Qual. 41:1750-1757 (this issue). doi: $10.2134 /$ jeq2012.0003

Veith, T., A. Sharpley, J. Weld, and W. Gburek. 2005. Comparison of measured and simulated phosphorus losses with indexed site vulnerability. Trans. ASAE 48:557-565.

Weld, J., and A.N. Sharpley. 2007. Phosphorus indices. In: D.E. Radcliffe and M.L. Cabrera, editors, Modeling phosphorus in the environment. CRC Press, Boca Raton, FL. p. 301-332. 